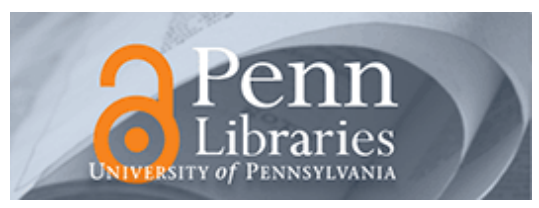

\title{
Studies in Visual Communication
}

Volume 4

Issue 1 Spring 1977

Article 2

1977

Introduction to "Cultural Influence on Perception"

Margaret Mead

\section{Recommended Citation}

Mead, M. (1977). Introduction to "Cultural Influence on Perception". 4 (1), 3-6. Retrieved from https://repository.upenn.edu/svc/vol4/iss1/2

This paper is posted at ScholarlyCommons. https://repository.upenn.edu/svc/vol4/iss1/2

For more information, please contact repository@pobox.upenn.edu. 


\section{Introduction to "Cultural Influence on Perception"}




\section{INTRODUCTION TO "CULTURAL INFLUENCE ON PERCEPTION"}

\section{MARGARET MEAD}

The core of this paper was written as a thesis at Temple University School of Fine Arts, soon after the author returned from a field trip to the Admiralty Islands, Papua New Guinea, where she had been a member of a research team. For The American Museum of Natural History Admiralty Islands Expedition in 1952, I had recruited Theodore Schwartz, who was then her husband and a graduate student at the University of Pennsylvania; Lenora became a valued third member of the team. Her training had been entirely in the fine arts, and she learned anthropological fieldwork primarily by direct identification. I realized immediately that her visual and kinesthetic type of perception complemented her husband's finely tuned ear, developed even more acutely during a period of impaired sight, and I counted on this complementary relationship to provide new insights for observation, photographing and filming of the Manus people, and for subsequent analysis of the film and photographs when we returned from the field.

The publication of this paper has been inordinately delayed, by a combination of factors; my original intention was to include it in a series of papers on the Allopsychic Orientation Project, which has never been published because of the dilatoriness of some of the proposed contributors. Then, in attempting to publish materials which demanded color, we ran into further reasons for delay. During the intervening years since she did the original fieldwork and wrote the version of this paper for her thesis, Lenora Foerstel has had many years of creative teaching at the Maryland Institute of Fine Arts and in adjacent institutions, and her conceptions of the relationships between anthropology and art have been steadily evolving. These growing conceptions have provided a changing framework for this final version of her paper. But the core remains as a fresh response to her field experience in 1953 to 1954. The beauty of anthropological fieldwork is that, like the lady on the Grecian urn, it does not fade. The fieldworker grows older and wiser, and those whom we study grow up, age and die, but the descriptions, made at a particular moment in the development of anthropological theory and a particular state of the art, remain.

This has become even more important because both our methods of recording, and the cultures which we study have been changing so rapidly. One of the little girls whom Lenora studied grew up to become advisor to the prime minister and wrote a sociological thesis on the Paliau Movement, which was the revitalization movement that was in full swing when we were there. Today, those children are scattered all over the new nation of Papua New Guinea, forming the intelligentsia of the new nation state.
It is important also for the reader to understand the particular situation into which I brought my young associates in 1953. In 1928-29, Reo Fortune and I had made an intnesive study of Peri, a village of the lagoon dwelling Manus people of the Admiralties. Our reports were published in my Growing Up in New Guinea and Kinship in The Admiralty Islands, and in Reo Fortune's Manus Religion. This study was made soon after pacification; warfare, raiding, capture of women from other tribes (as prostitutes) had been forbidden and there was a population of returned, indentured laborers dating back to the pre-World War I, German colonial period. At that time, photographic methods were still very unmanageable; we had to develop the negatives the day they were taken, and it was only feasible to do so in the dark of the moon; we used tray development. So, we had the usual small collection of still photographs, no film, and no sound recording. In the course of showing photographs of the Manus to the Gesell-IIg team at the Gesell Institute in New Haven, I found that, even though the photographs had been taken in such an exigent manner, it was possible for Frances Ilg to say a great deal about the children from looking at their posture, stance and physique, although she had no other knowledge of Manus culture. On the strength of that experience, I decided that we would include somatotyping in my proposed restudy in 1953, and plan for extensive film recording of the sort that Gregory Bateson and I had done in Bali and among the latmul of the Sepik River, Papua New Guinea in 1936-39. Ted Schwartz had been chosen partly because he had taken the trouble to develop photographic skills; during the years before we went into the field, both Ted and Lenora had extensive practice with the equipment we proposed to use, and exposure to the Balinese work. It was against this background that the photographs used in this monograph were taken, and Lenora's analysis made.

In 1928, the Manus people lived in lagoons, in houses built on stilts over the water; the land people, the Usiai, lived inland on the Great Admiralty, which was the center of the Admiralty Island archipelago. Manus and Usiai traded with each other in frequent set markets, the Manus bringing sea products and Usiai land products. Individual Manus and Usiai men had trade friendships which assured each immunity from attack in the villages of the other; there were occasional intermarriages which then were followed by affinal and eventually more hereditary trade relationships. Usiai villages were sometimes allies of Manus villages against other Usiai and Manus villages in the pre-contact period. But on the whole, the relationship was one of contempt on the Manus side, and a sense of galling inferiority on the Usiai side.

During World War II, the Admiralty Islands were occupied first by the Japanese and subsequently Manus became the staging area for the advance into the Pacific, the largest American installation between Pearl Harbor and Guam. Manus and Usiai men, away at work at the beginning of hostilities, were caught behind the lines and exposed to both Japanese and Allied troop behavior, while those who remained at home had a chance to observe the large scale occupation activities on Manus itself. All the people of the Admiralties had been converted to Christianity beginning before World War I, and the peoples of the South Coast were all Roman Catholics, hence the frequent occurrence of 
Christian names. In 1946, a man from the island of Baluwan, where there was an extensive Manus lagoon settlement called Mok, returned to Manus and initiated a sweeping political movement which, assisted by a cargo cult, swept through all the Manus villages, involved part of Usiai villages, and villages on other, smaller South Coast islands. This was called in pidgin English, the New Fela Fashion, to which Lenora refers. Under the leadership of Paliau, the lagoon dwelling Manus villages were all moved ashore and the recruited sections of the mountain dwelling Usiai were brought down to the sea coast. Peri village, where Reo Fortune and I had worked in 1928-29, remained as a purely Manus village, but Bunai, where Ted Schwartz and Lenora were stationed, was a composite village formed from previous Manus lagoon dwelling villages and mountain Usiai villages. Under the ideology of the New Fela Fashion, or NFF, all the peoples of the Admiralties were to become brothers and sisters in the new order; the land people were to learn to handle canoes and fish, and the lagoon people were to learn to plant vegetable foods; sago land was to be socialized, widows and orphans were to become the responsibility of the village as a whole, and harmony was to prevail. In actuality, many of the old hostilities, jealousies and animosities remained and remain to this day. Ted's and Lenora's house was fortunately situated in the middle of the long village and children from both groups frequented there and were available for testing and exploratory games.

Some of the results of the 1953-54 field trip have been published in Ted Schwartz's The Paliau Movement in the Admiralty Islands, 1946-1954 and my New Lives for Old, where I also present comparative observations on the children in the two periods and notes and photographs illustrating our change in method over the twenty-five year period. If the reader feels a need for further ethnographic and historical background for the discussions in this monograph, it can be found in these two volumes and in other publications by Ted Schwartz and me.

At the time of the 1953-54 field trip, it was easy to explain the way the sea dwelling peoples had taken the lead in the new political movement. As sailors and sea traders they were more open to innovation, embraced new customs more rapidly, and learned very rapidly when given a chance at schooling. Subsequently, however, as all the children of the Admiralties have gained access to schooling in their villages, in the Manus high school and in higher education off the island, the Usiai children have competed successfully with the coastal and small island people. Within the climate of expected high achievement for Admiralty Islanders, they have shown themselves ready to take advantage of the new opportunities and to overcome temporary handicaps experienced when they moved to the coast. They learned the marine techniques practiced by the lagoon dwelling Manus, while the Manus themselves showed little proclivity for agriculture. In 1965, the South Coast Council, founded by the Paliau movement, merged with the North Coast Council; there is less parochial and ideological intransigence, and some of the Bunai Usiai have returned to live on their traditional inland gardening territories.

I am distressed over the delay in the publication of this unique study, but I am somewhat comforted by the fact that the material will be much more intelligible to a much wider audience than it would have been in the mid 1950s, before the field of semiotics (see Sebeok, Hayes and Bateson 1964) had been developed, or very much was known about the cross cultural use of the Lowenfeld Mosaic Test. The subtle contrasts which Lenora found between the kinesics of the Manus and Usiai enrich our knowledge of culture specific behaviors. They will eventually be fitted in also with the later studies of Manus, which have been made in the 1960s and early 1970 s by Ted Schwartz, Lola Romanucci Ross, Barbara Honeyman Heath, Fred Roll, and Lawrence Malcolm and by the further field trips which Lenora Foerstel hopes to make next year. 


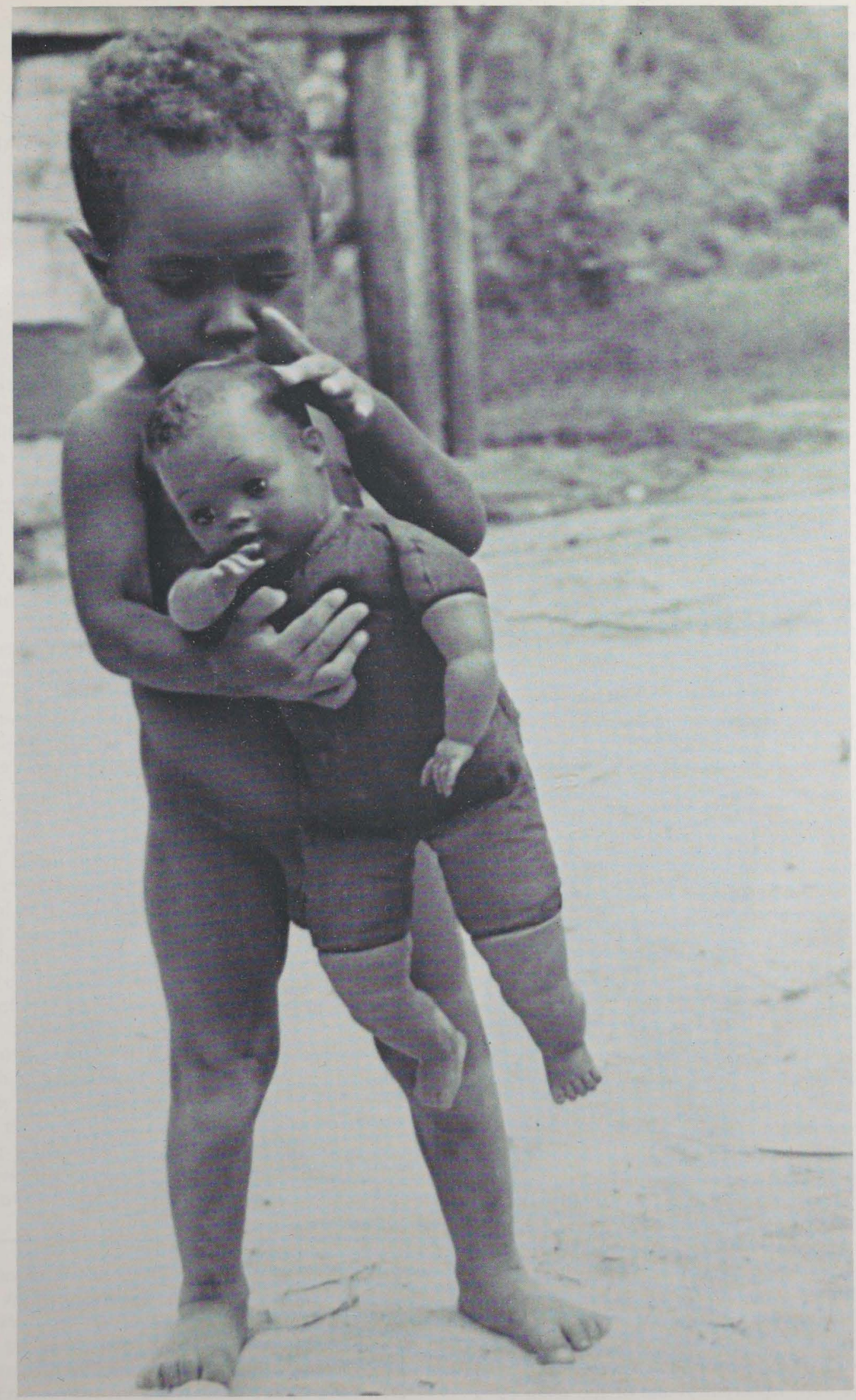

Frontispieces pages $5 \& 6$, plates $1 \& 2$-Manus, Bunai, January 13, 1954. Manus child examining an American-made doll. 


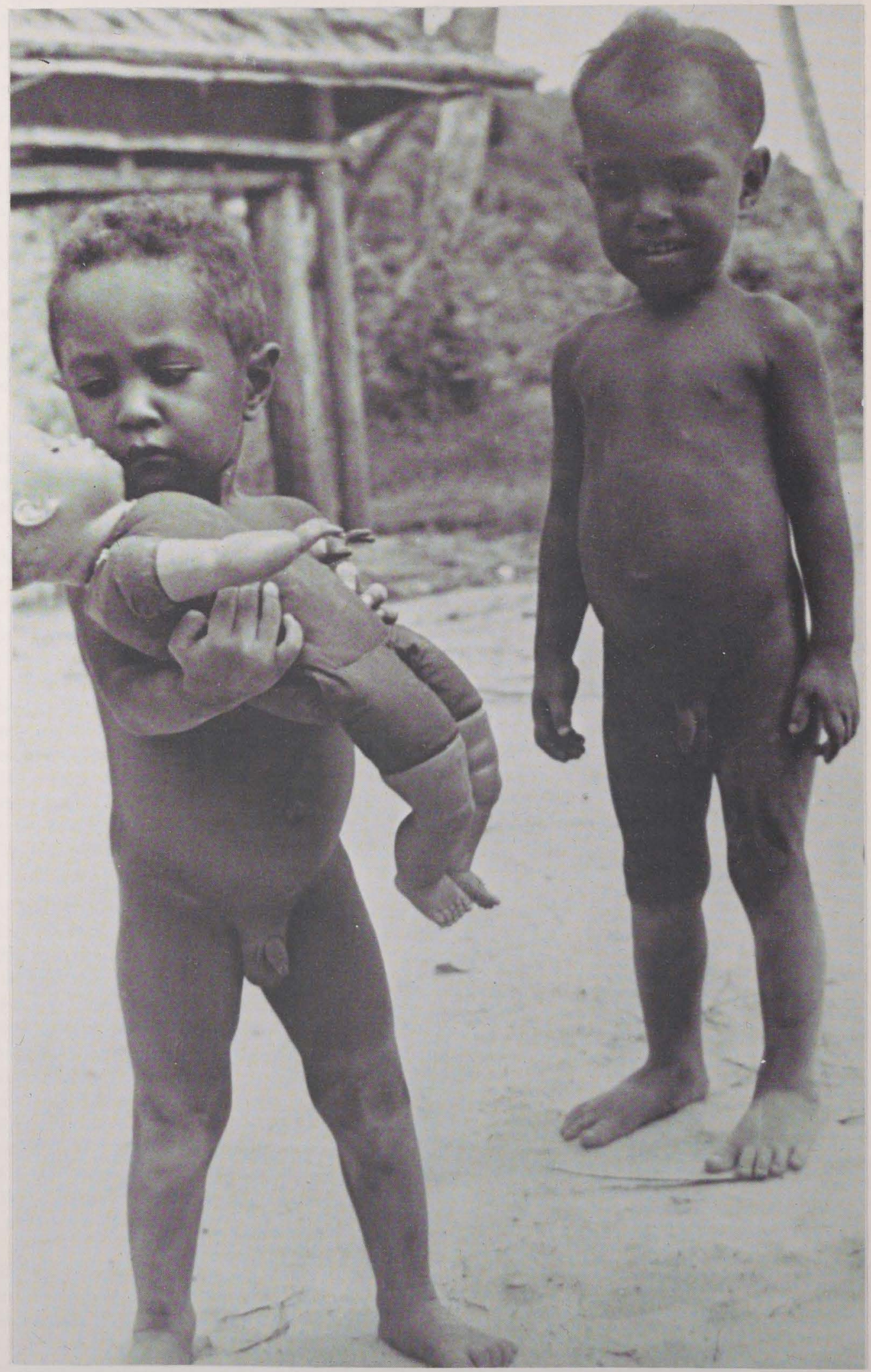

